\title{
Experimental Work on Micro Laser-Assisted Diamond Turning of Silicon (111)
}

\author{
Hossein Mohammadi $^{1 *}$, Deepak Ravindra ${ }^{2}$, Sai K. Kode ${ }^{2}$ \\ and John A. Patten ${ }^{1}$ \\ ${ }^{1}$ Western Michigan University, Kalamazoo, MI, USA. \\ ${ }^{2}$ Micro-LAM Technologies, Battle Creek, MI, USA \\ hossein.mohammadi@wmich.edu,deepak.ravindra@micro-lam.com \\ saikumar.kode@micro-lam.com, john.patten@wmich.edu
}

\begin{abstract}
Single point diamond turning (SPDT) is coupled with the micro-laser assisted machining ( $\mu$-LAM) technique to machine silicon (111). The $\mu$-LAM system is used to preferentially heat and thermally soften the work piece material in contact with a diamond cutting tool. Cutting fluid, odorless mineral spirits (OMS), is used to decrease tool wear and improve the surface quality. An IR continuous wave (CW) fiber laser, wavelength of $1070 \mathrm{~nm}$ and max power of $100 \mathrm{~W}$ with a minimum beam diameter of $10 \mu \mathrm{m}$, is used in this investigation. Various machining parameters such as laser power, cross feed rate and tool rake angle were experimented and the resultant surface finish was analyzed. Results show that an optical quality surface finish can be obtained using the $\mu$-LAM technique.
\end{abstract}

Keywords: $\mu$-LAM, Silicon, SPDT, Laser, Surface finish

\section{Introduction}

Single crystal silicon is a very important material with many applications in MEMS, electronics and optoelectronics. It is hard, strong, and light weight, and can easily be used in microfabrication. When attempting to machine ceramics and semiconductors, such as silicon especially to improve the surface finish, it is important to carry out a "damage free" machining operation. Often, severe fracture can result during the machining process due to the material's low fracture toughness ( 0.83 to 0.95 MPa. $\mathrm{m}^{0.5}$ for silicon based on direction). Brittle fracture occurrence during process results in poor surfaces and causes detrimental subsurface damage, which then has to be removed in subsequent processing steps such as polishing or lapping (Ravindra et al., 2012).

Machining mirror-like surface finishes contribute significantly to the total cost of a part. The cost is mainly due to many parameters such as expensive tools that wear out rapidly, long machining time,

${ }^{*}$ Lead and corresponding author 
low production rate to get acceptable surface roughness and etc. In some cases, polishing alone can account for $60-90 \%$ of the final product cost (Wobker \& Tonshoff, 1993). The low production rate is primarily due to the occurrence of surface/subsurface damages, i.e., cracks and brittle fracture. In order to develop a suitable process, ductile regime machining, considered to be one of the acceptable precision machining techniques, has been continuously studied over the last two decades (Blackley \& Scattergood, 1994; Morris et al., 1995; Leung et al., 1998; Sreejith \& Ngoi, 2001; Yan et al., 2004; Patten et al., 2003; Patten et al., 2005; Dong \& Patten, 2007; Ravindra \& Patten, 2011). In these researches, it has been demonstrated that ductile regime machining of semiconductor and ceramic materials is possible due to the high-pressure phase transformation (HPPT) occurring in the material caused by the high compressive and shear stresses induced by the single point diamond tool tip (Tanikella et al., 1996; Jasinevicius et al., 2005; Gogotsi et al., 2001; Zhou et al., 2001; Patten et al., 2007; Ravindra \& Patten, 2011; Wu \& Melkote, 2012). To further augment the ductile response of these materials, traditional SPDT is coupled with the micro laser assisted machining ( $\mu$-LAM) technique (Ravindra et al., 2012; Shayan et al., 2009; Ravindra et al., 2010; Ravindra et al., 2012; Mohammadi et al., 2013). Previous feasibility tests have successfully demonstrated the use of IR fiber laser and green laser (Mohammadi et al., 2013) to preferentially heat and soften the high pressure metallic phase of silicon during scratching, which is the essence of the $\mu$-LAM system. A schematic of the working process is shown in Figure 1. As seen in figure 1, a laser beam is transmitted through an optically transparent diamond (cutting tool) and focused precisely at the tool-workpiece interface, where the material is under high pressures induced by the diamond tool. Under high compressive stresses, a high-pressure phase transformation occurs. The HPPT zone then absorbs the laser radiation to soften the material which leads to lower cutting forces.

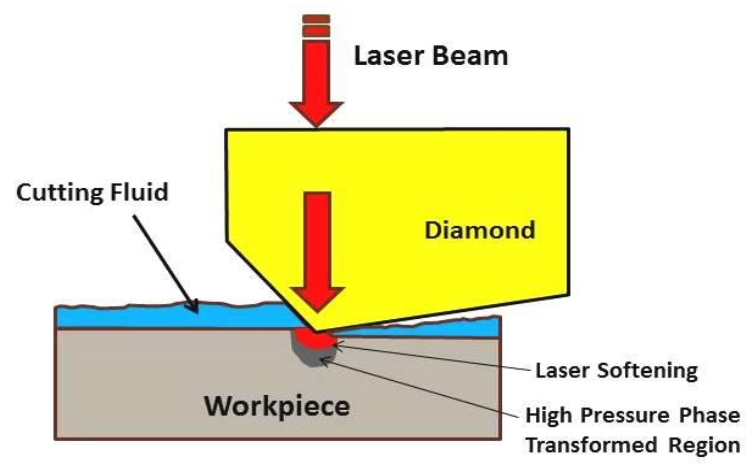

Figure 1: Schematic of the $\mu$-LAM process with cutting fluid

In the present research, the effect of $\mu$-LAM on the surface roughness and material removal rate of single crystal silicon has been studied. Previous studies of this group were on semiconductor grade silicon (100) wafers (Ravindra et al., 2010; Mohammadi et al., 2013; Mohammadi et al., 2014; Mohammadi et al., 2014), while in the current work optical grade silicon (111) is under focus.

\section{Experimental}

Single crystal optical grade silicon (111) with a diameter of $28.1 \mathrm{~mm}$ was selected to be machined in this experimental study. A $1 \mathrm{~mm}$ nose radius single crystal diamond cutting tool was used for this set of experiments. An IR CW diode laser $\left(\lambda=1070 \mathrm{~nm}\right.$ and $\left.\mathrm{P}_{\max }=100 \mathrm{~W}\right)$ with a Gaussian beam profile and minimum diameter of approximately $10 \mu \mathrm{m}$ is used. The laser beam is guided through a single mode fiber optic cable to a collimator, which is attached to a Beam Delivery Optics (BDO) unit. 
The BDO then converges the beam and delivers it through the diamond cutting tool as figure 2. Other function of the BDO is aligning the beam by moving the tool in a plane perpendicular to the beam axis.

A Moore Nanotech 350FG diamond turning machine was used for the experiments. A tool post compatible with the BDO was attached to the diamond turning machine to perform the laser assisted machining experiments. Even though the resulting tool wear with the laser ( $\mu$-LAM technique) is significantly lower than with no laser, odorless mineral spirit (OMS) as cutting fluid is added to further minimize the tool wear and to assist with flushing the machined chips away. The experimental setup used for machining silicon sample is shown in figure 2 . The $\mu$-LAM process does not have limitations that other processes and techniques utilizing thermally soften by preheating the material or shining the laser in front of the tool have. For those processes, use of cutting fluid interrupts the laser beam path and cools down the workpiece, however in $\mu$-LAM, the laser is shining through the diamond tool and only softens a region of the material in contact with the tool. A combination of mechanical machining and laser softening and at same time using the cutting fluid is one of the unique advantages of this process. There are many parameters to evaluate including machining parameters (speed, feed, depth, cutting fluid), optical parameters (laser power, wavelength, and beam size), cutting tool type (single crystal, polycrystals, nanocrystalline amorphous) and etc. However machining parameters used in this test are summarized in Table 1.

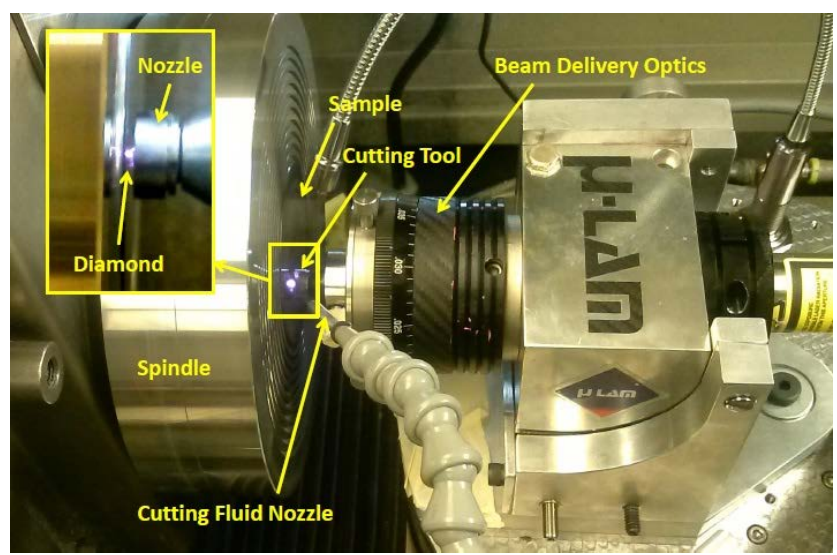

Figure 2: Micro-LAM setup mounted on a diamond turning machine

Table 1: Machining parameters

\begin{tabular}{ll}
\hline Machining Parameters & Values \\
\hline Spindle rotational speed & $2000 \mathrm{RPM}$ \\
Laser power* & $0,20 \mathrm{~W}, 30 \mathrm{~W}$ \\
Roughing feed rate & $4 \mu \mathrm{m} / \mathrm{rev}$ \\
Roughing depth of cut & $10 \mu \mathrm{m}$ \\
Finishing feed rate & $1 \mu \mathrm{m} / \mathrm{rev}$ \\
Finishing depth of cut & $5 \mu \mathrm{m}$ \\
\hline
\end{tabular}

* Actual output at the tool tip is about $40 \%$ due to scattering, reflection and etc. 


\section{Results and Experimental Data}

Ductile mode $\mu$-LAM (coupled with SPDT) was carried out on unpolished side of the single crystal silicon (111) with a starting surface roughness of $\sim 770 \mathrm{~nm}(\mathrm{Ra})$. The surface roughness of each region was measured after machining using a white light interferometric profilometer. The machined surfaces are also observed by an optical microscope to find any signs of brittle mode or imperfection. Achieving a high quality surface finish is very challenging and therefore machining parameters should be selected carefully. Adding the laser as a new parameter increases the level of complexity in the optimization process.

A roughing pass is done to flatten the sample, primarily to avoid an interrupted cut for the finishing pass. The roughing pass was carried out with and without the laser to study the effects on improving surface roughness. The cuts were programmed at a $10 \mu \mathrm{m}$ depth of cut, along with a $4 \mu \mathrm{m} / \mathrm{rev}$ cross feed. The roughing pass without the laser had a surface roughness of $80 \mathrm{~nm}$ Ra compared to a $16 \mathrm{~nm}$ $\mathrm{Ra}$ with optimal laser power (see figure 3). At the $4 \mu \mathrm{m} / \mathrm{rev}$ feed rate, there is a possibility for 'pull outs' in the sample, but due to the laser heating effect, pull outs have been significantly reduced resulting in a better surface quality. In fact laser heating decreases the brittleness of the material and avoids brittle fracture of material in the machining region. An optical microscopic image of the unmachined silicon surface at 400x is shown in figure 4-a. Figure 4-b also shows the surface machined in conventional way with no laser. Although ductile mode machining with minimal surface damages was attempted, many imperfections can be observed due to partially brittle mode machining and pit/voids caused by cutting process.

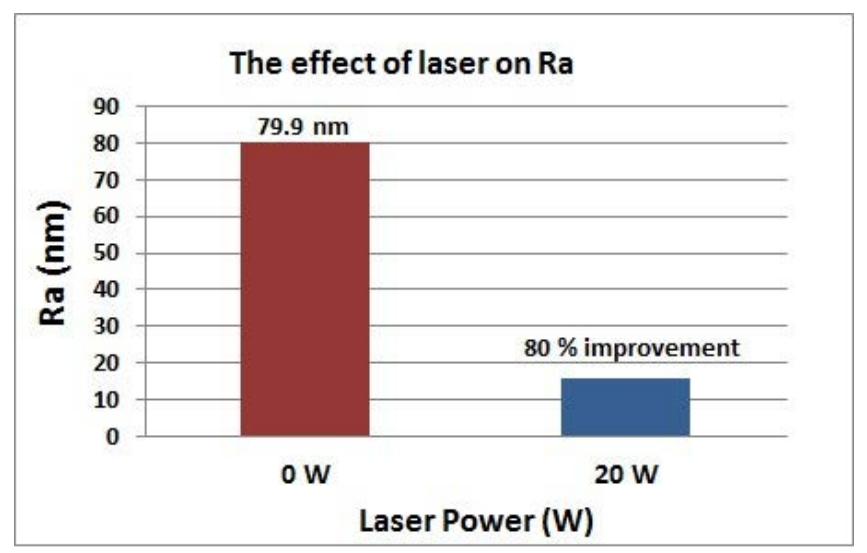

Figure 3: Effect of laser power on surface finish for the roughing pass

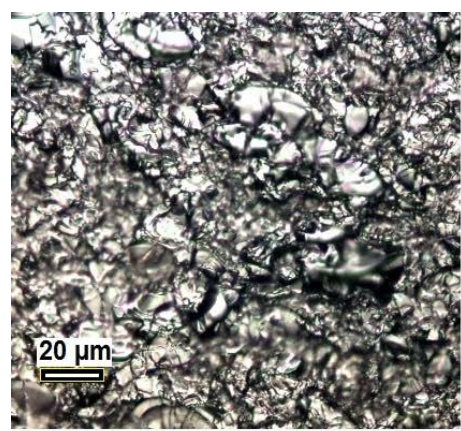

a

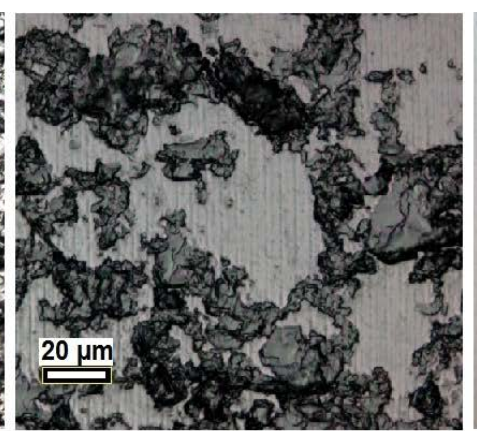

b

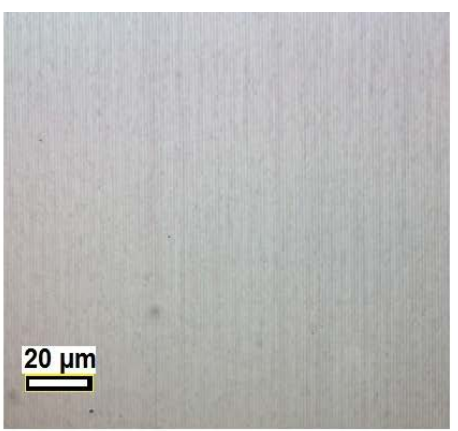

C

Figure 4: Unmachined (a), Conventionally (no laser) machined (b), $\mu$-LAM machined (c) 
The laser power selection for the finishing pass is more important than roughing pass because of its lower feed rate that could cause undesired thermal effects such as overheating. In this situation, since consecutive passes are very close to each other - and the beam diameter is much larger than the feed rate - the accumulated heat exceeds the optimal amount. Overheating in low range will cause the material to flow to the side of the tool nose and build up. In higher range (higher power) can cause other effects such as thermal cracks and even burning which would result in a rougher surface. Figure 5 shows the effect of excessive laser heating on the machined surface finish with $160 \%$ increase in surface roughness compared to the optimum laser power $(20 \mathrm{~W})$. The resulted surface finish with a laser power of $20 \mathrm{~W}$, cross feed of $1 \mu \mathrm{m} / \mathrm{rev}$ and $5 \mu \mathrm{m}$ depth of cut, was less than $10 \mathrm{~nm} \mathrm{Ra}$ as shown in figure 5 and actual surface in figure $4-c$.

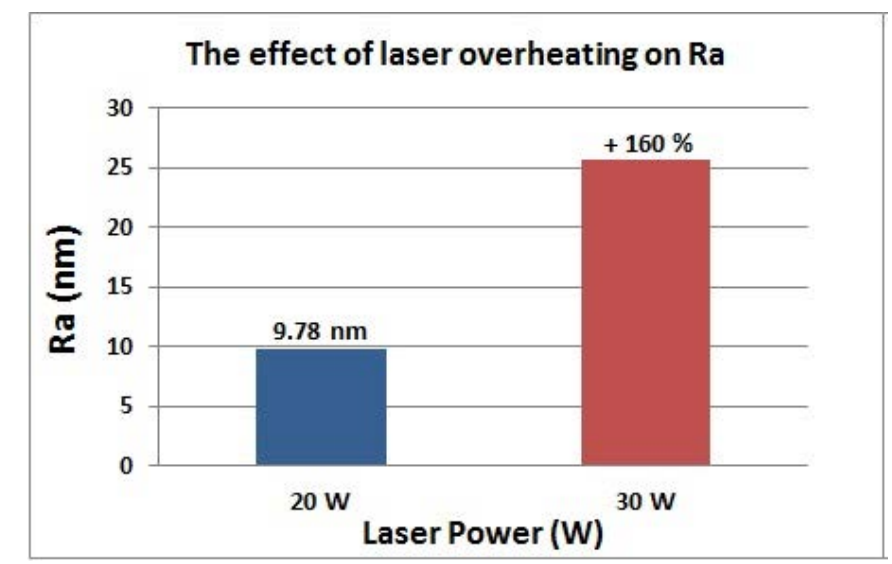

Figure 5: The effect of laser overheating on the surface roughness

The tool rake angle plays another very important role in achieving good surface finishes. A high negative rake tool will exert higher compressive forces that are necessary for machining hard ceramics such as silicon to achieve HPPT. Ceramics in general can withstand high compressive forces but very little tensile forces due to their low fracture toughness. Selecting the appropriate rake angle is necessary to achieve the best surface finishes. A very high negative rake angle on the other hand could result in rubbing of the surface which will result in low MRR, high tool wear and even a poor surface finish. The results presented in figure 6 obtained from a $2 \mu \mathrm{m}$ depth of cut and a $1 \mu \mathrm{m} / \mathrm{rev}$ feed show that a $-25^{\circ}$ tool yields a better surface finish with $\mathrm{Ra}$ of $3.2 \mathrm{~nm}$. One of the reasons to get the better surface finish with lower rake angle is that a better chips flushing happens by using $-25^{\circ}$ rake angle tool.

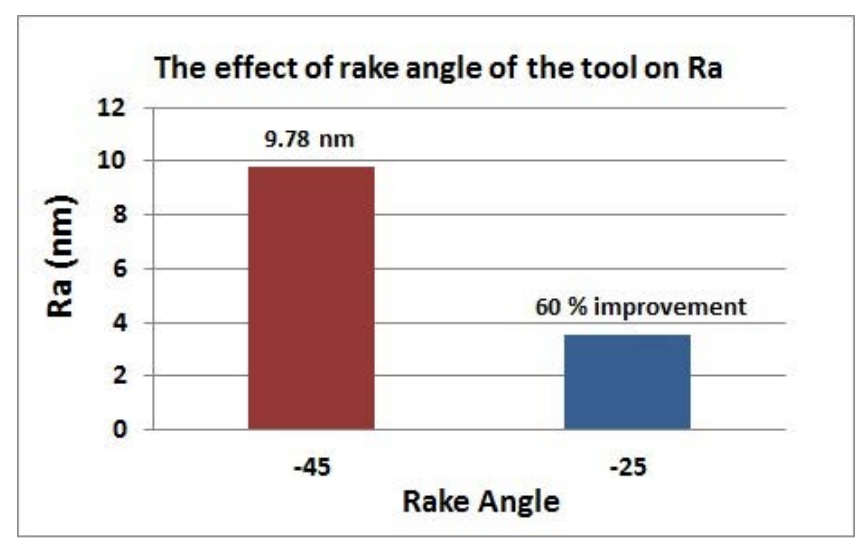

Figure 6: Effect of rake angle on surface finish 
One of the most common problems in machining single crystal silicon is the crystallographic orientation effect. In this situation, single point diamond turned silicon shows radial spokes of damages, where one of the early papers that studied this problem was by Blackley and Scattergod (1990) that they explained it for (111) slip planes. The key point is to keep the depth of cut lower than the critical depth which by exceeding it material removal will be in brittle mode (Patten et al., 2004). This phenomenon is observed in a test with no laser with a $4 \mu \mathrm{m} / \mathrm{rev}$ cross feed and $10 \mu \mathrm{m}$ depth of cut as figure 7. However, by using the laser, it is possible to get rid of those radial spokes. Figure 8 shows three samples: an unmachined sample machined with no laser and a sample machined with optimum laser power. The sample machined with no laser has radial spokes while the one machined with the laser is mirror like surface finish with no sign of surface damages.

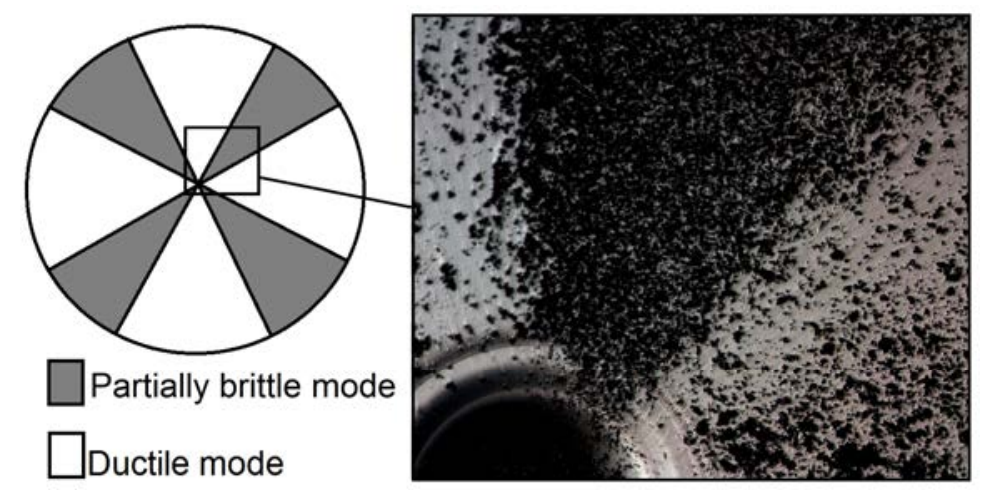

Figure 7: Crystallographic orientation effect in machining single crystal silicon

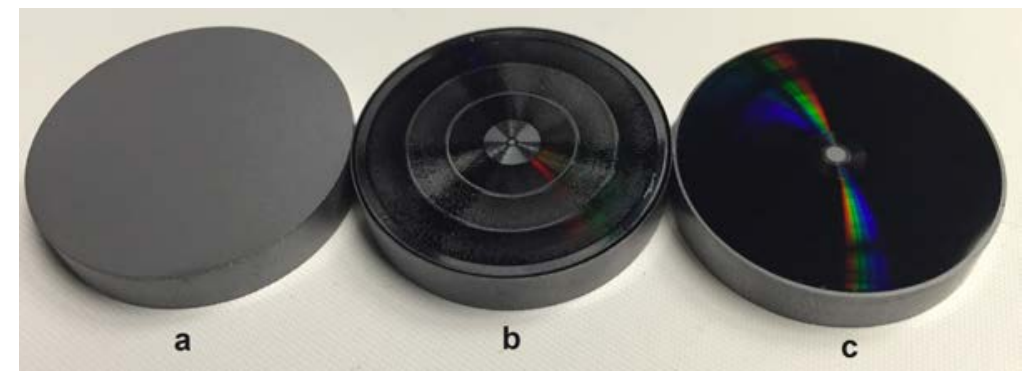

Figure 8: Silicon sample: Unmachined (a), machined with no laser (b) and machined with laser (c)

\section{Conclusion}

A combination of laser heating and SPDT for machining of optical grade single crystal silicon (111) was successful in reducing the surface roughness significantly. The Ra was brought down from $770 \mathrm{~nm}$ to $3.2 \mathrm{~nm}$ which is a very promising result. Radial spokes that occur during the machining of single crystal silicon due to crystallographic orientation effect can be "healed" and eliminated using the $\mu$-LAM process. One of the unique advantages of the $\mu$-LAM process is that the advantages of laser softening and cutting fluids can be exploited simultaneously with no laser beam interruption. It has been shown that using the optimum laser power is very crucial in this process and should be selected carefully to not overheat the sample. 


\section{Acknowledgements}

The authors would like to thank the National Science Foundation (SBIR Phase I/IB Award \#:IIP1214772 and SBIR Phase II Award \#:IIP-1330439) for funding this study.

\section{References}

Blackley, W., \& Scattergood, R. (1990). Crystal Orientation Dependence of Machning Damage-A Stress Model. Journal of the American Ceramic Society, 73(10), 3113-3115.

Blackley, W., \& Scattergood, R. (1994). Chip topography for ductile-regime machining of germanium. Journal of Manufacturing Science and Engineering, 116(2), 263-266.

Dong, L., \& Patten, J. (2007). Real time infrared (IR) thermal imaging of laser-heated high pressure phase of silicon. In Advanced Laser Applications Conference \& Expo (ALAC 2007), September 2007, 24-25.

Gogotsi, Y., Zhou, G., Ku, S., \& Cetinkunt, S. (2001). Raman microspectroscopy analysis of pressureinduced metallization in scratching of silicon. Semiconductor science and technology, 16(5), 345.

Jasinevicius, R., Porto, A., Duduch, J., Pizani, P., Lanciotti Jr, F., \& dos Santos, F. (2005). Multiple phase silicon in submicrometer chips removed by diamond turning. Journal of the Brazilian Society of Mechanical Sciences and Engineering, 27(4), 440-448.

Leung, T. P., Lee, W. B., \& Lu, X. M. (1998). Diamond turning of silicon substrates in ductile-regime. Journal of Materials Processing Technology, 73(1), 42-48.

Mohammadi, H., Poyraz, H., Ravindra, D., \& Patten, J. (2014). Single Point Diamond Turning of Silicon by Using Micro-Laser Assisted Machining Technique. In ASME 2014 International Manufacturing Science and Engineering Conference collocated with the JSME 2014 International Conference on Materials and Processing and the 42nd North American Manufacturing Research Conference (V002T02A057-V002T02A057).

Mohammadi, H., Poyraz, H., Ravindra, D., \& Patten, J. (2014). An experimental study on Single Point Diamond Turning of an unpolished Silicon wafer via Micro-Laser Assisted Machining. In Advanced Materials Research, Vol. 1017, 175-180.

Mohammadi, H., Ravindra, D., \& Patten, J. (October 2013) A First Investigation Of Green Lasers In Micro-Laser Assisted Scratch Tests On Silicon. In the 28th annual meeting American Society of Precision Engineering, St. Paul, Minnesota, USA, October 20 - 25, 2013.

Morris, J., Callahan, D., Kulik, J., Patten, J., \& Scattergood, R. (1995). Origins of the Ductile Regime in Single-Point Diamond Turning of Semiconductors. Journal of the American Ceramic Society, 78(8), 2015-2020.

Patten, J., Cherukuri, H., \& Yan, J. (2004). Ductile-regime machining of semiconductors and ceramics. High-Pressure Surface Science and Engineering, Y. Gogotsi, and V. Domnich, eds., Institute of Physics, Bristol, UK.

Patten, J., Fesperman, R., Kumar, S., McSpadden, S., Qu, J., Lance, M., Nemanich, R. \& Huening, J. (2003). High-pressure phase transformation of silicon nitride. Applied physics letters, 83(23), 4740-4742.

Patten, J., Gao, W., \& Yasuto, K. (2005). Ductile regime nanomachining of single-crystal silicon carbide. Journal of manufacturing science and engineering, 127(3), 522-532.

Patten, J., Jacob, J., Bhattacharya, B., \& Grevstad, A. (2007). Comparison between numerical simulations and experiments for single point diamond turning of silicon carbide. Transactions NAMRI/SME, 35, 89-96. 
Ravindra, D., Ghantasala, M., \& Patten, J. (2012). Ductile mode material removal and high-pressure phase transformation in silicon during micro-laser assisted machining. Precision engineering, 36(2), 364-367.

Ravindra, D., \& Patten, J. (2011). Chapter 4: Ductile regime material removal of silicon carbide (SiC). Silicon Carbide: New Materials, Production methods and application, SH Vanger, ed., Nova Publishers, Trivandrum, India, 141-167.

Ravindra, D., \& Patten, J. (2011). Ductile Regime Single Point Diamond Turning of Quartz Resulting in an Improved and Damage-Free Surface. Machining Science and Technology, 15(4), 357-375.

Ravindra, D., Patten, J. \& Ghantasala, M. (2012). Effect of Applied Load, Cutting Speed and Laser Power on the Material Deformation and Removal of Semiconductors, Proceedings of the $40^{\text {th }}$ North American Manufacturing Research Conference (NAMRC 40), Indiana, USA, June 4-8 2012.

Ravindra, D., Poyraz, B., \& Patten, J. (2010). The effect of laser heating on the ductile to brittle transition of silicon. In The 5th International Conference on MicroManufacturing (ICOMM/4M), Wisconsin, USA, April 5-8 2010.

Shayan, A., Poyraz, H., Ravindra, D., Ghantasala, M., \& Patten, J. A. (2009). Force Analysis, Mechanical Energy and Laser Heating Evaluation of Scratch Tests on Silicon Carbide (4H-SiC) in Micro-Laser Assisted Machining ( $\mu$-LAM) Process. In ASME 2009 International Manufacturing Science and Engineering Conference, 827-832.

Sreejith, P., \& Ngoi, B. (2001). Material removal mechanisms in precision machining of new materials. International Journal of Machine Tools and Manufacture, 41(12), 1831-1843.

Tanikella, B., Somasekhar, A., Sowers, A., Nemanich, R., \& Scattergood, R. (1996). Phase transformations during microcutting tests on silicon. Applied physics letters, 69(19), 2870-2872.

Wobker, H., \& Tonshoff, H. (1993). High-efficiency grinding of structural ceramics. NIST Spec. Publ., 847, 171.

Wu, H., \& Melkote, S. (2012). Study of ductile-to-brittle transition in single grit diamond scribing of silicon: application to wire sawing of silicon wafers. Journal of Engineering Materials and Technology, 134(4), 041011.

Yan, J., Maekawa, K., Tamaki, J., \& Kubo, A. (2004). Experimental study on the ultraprecision ductile machinability of single-crystal germanium. JSME International Journal Series C, 47(1), 29-36.

Zhou, M., Ngoi, B., Zhong, Z., \& Chin, C. (2001). Brittle-ductile transition in diamond cutting of silicon single crystals. Materials and Manufacturing Processes, 16(4), 447-460. 